\title{
Polimero akrilikoak oftalmologian. Degradazio-prozesuaren analisia
}

\author{
(Acrylic based polymers in Oftalmology. \\ Analysis of the degradation processes)
}

\author{
Aitor de Miguel ${ }^{1}$, Mikel Azkune ${ }^{2}$, Leire Ruiz-Rubio ${ }^{1 *}$ \\ ${ }^{1}$ Kimika Fisikoa Saila, Zientzia eta Teknologia Fakultatea \\ (UPV/EHU) \\ ${ }^{2}$ Fotonika Aplikatu Taldea, Komunikazio Ingeniaritza Saila, \\ Bilboko Ingeniaritza Goi Eskola Teknikoa (UPV/EHU)
}

*leire.ruiz@ehu.eus

DOI: $10.1387 /$ ekaia.16310

Laburpena: Ukipen-leiar polimerikoen erabilpena zabaltzen ari da munduko gizarte orotan. Gaur egungo lenteetara iristeko eman diren aurrerapauso guztiek oinarri akrilikodun materialen erabilpena izan dute amankomunean, ezaugarri optiko paregabeak dituztelako. Hori dela eta, lan honetan material horien historia, ukipen-leiarren bilakaera eta polimerozko material optikoek bete beharreko baldintzak azaltzen dira. Horrez gain, industria honetan erabiliak izan diren poli(metilmetakrilato)aren, poli(bentzilakrilato)aren eta poli(tert-butilakrilato)aren degradazio termikoak eta beren zinetika aztertu dira.

Hitz gakoak: polimero akrilikoak, degradazio termikoa, termograbimetria, zinetika.

\begin{abstract}
The use of polymeric contact lenses has risen worldwide the last years. During the development of these lenses, acrylic based materials have aroused as the most used polymers due to their optical properties. Taking into account the importance of these polymers, in this work we have explained the history and evolution of the contact lenses together with the properties that optical materials must have. Moreover, three commonly used polymers have been chosen, poly(methylmethacrylate), poly(benzylacrylate) and poly(tert-butylacrylate), and their thermal degradation and their kinetic have been studied.
\end{abstract}

Keywords: acrylic polymers, thermal degradation, kinetics. 


\section{SARRERA}

Gaur egungo gizartean, oso barneratuta dago ikusmen-arazoak zuzentzeko helburuarekin tresna ezberdinen erabilpena, betaurrekoak edo ukipen-leiarrak besteak beste. Aukeren artean, erabiltzaile askok egiten dute ukipen-leiarren aldeko hautaketa erosotasunak edo gutxieneko itxura-aldaketak bultzatuta (1. irudia). Estatistikek diote Ameriketako Estatu Batuetan soilik, 30 milioi pertsona baino gehiagok daramatzatela eta zenbaki hori handitzen ari dela urtetik urtera [1].

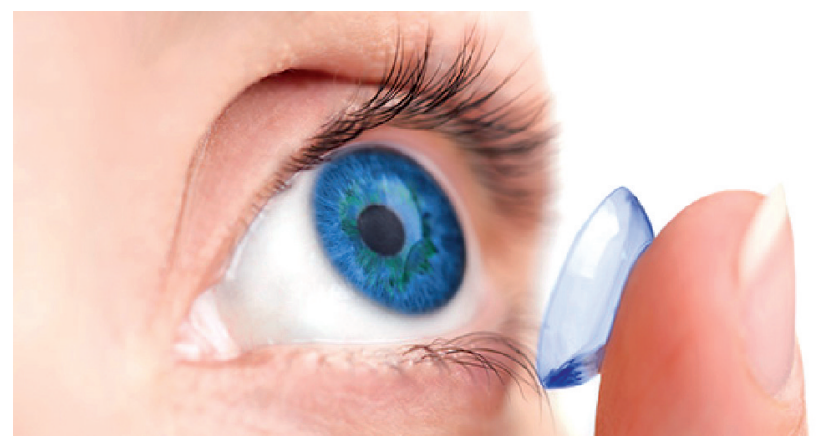

1. irudia. Ukipen-leiarra begian jartzen.

Merkatu-zifra horiekin industria garrantzitsua bilakatu da eta material edo lente berrien ikerkuntzak indar handia hartu du. Honenbestez, material optikoei buruzko ideia nagusiak, ukipen-leiarrek zein ezaugarri dituzten edo zein materialez eginak dauden eta izan ohi dituzten ezaugarriak deskribatuko dira lan honetan.

\subsection{Material optikoak}

Instrumentazio optikoak argia moduren batean tratatu, anplifikatu edo eraldatzen duten tresna edo osagaiak dira. Izan ere, material horiek zenbait ezaugarri bete beharko dituzte prozesaketa egokia izan dezan argiak [2]. Gehienetan, beirazkoak edo polimerozkoak izaten dira; lehenengoak garestiagoak izan dira betidanik, baina zehatzagoak era berean. Polimerozkoek, ordea, nahiz eta kalitate kaskarragokoak izan, gaur egun beste ezaugarri batzuk eskaintzen dituzte eta, azken urteetako ikerkuntza eta aurrerapenei erreparatuta, efektu hobeak lor daitezke.

\subsubsection{Ezaugarriak}

Lenteetan, objektiboetan, ispiluetan edo uhin-gidetan garrantzi handia du materiala nolakoa den ezagutzeak argiaren erantzuna jakiteko eta, 
horrela, argia kontrolatzeko. Horretarako, honako ezaugarriei erreparatu beharko zaie:

*Espantsio koefiziente termikoa. Koefiziente honek objektu optikoak jasaten duen aldaera giro-tenperaturarekiko azaltzen du, zehatz-mehatz, bolumen aldaketa nominala gradu zentigraduko, betiere presio konstante batean. Adierazle hori muntaiak egiterako orduan edo muntaiek tenperatura-aldaketa bortitzak jasan behar dituztenean bakarrik izango da esanguratsua.

*Transmisio-balioa uhin-luzerarekiko. Argi-transmisioa definitzerako orduan, kontuan izan behar da ezaugarri hori materialak uhin-luzera zehatz batean argia garraiatzeko duen gaitasuna dela, materialak berak argia absorbatuz maila handiagoan edo txikiagoan. Beraz, material bakoitzak uhinluzera ezberdinak garraiatuko ditu eta luzera talde horri transmisio-leihoa deritzo. Normalean, material optikoak argi ikusgaia zein infragorri eta ultramore hurbileko zenbait uhin-luzera transmititzeko diseinatzen dira.

*Ezaugarri mekanikoak. Egin nahi den sistema optimoa izan dadin, osagaien gogortasuna, dentsitatea eta elastikotasuna kontuan izan beharreko parametroak dira. Normalean, polimeroz eginiko osagaiek dentsitate baxuagoa izaten dute beirazkoekin alderatuta; horregatik, arinagoak izan ohi dira. Muntaiaren aplikazioek gogortasun eta egonkortasun handia eskatzen badute, kontuan hartu beharko da.

*Kostua. Kostua izaten da, kasurik gehienetan, gehien baldintzatzen duen faktorea. Osagaien fabrikazio-materiala eta horren prozesatzea izaten dira prezioan eraginik handiena duten ezaugarriak. Gaur egun, polimerozko osagaiak merkeagoak izaten dira.

\subsubsection{Material akrilikoak}

Oftalmologian eta optika orokorrean erabiltzen diren polimero gehientsuenek oinarri akrilikoa izaten dute. Lotura bikoitzez elkartutako bi karbono terminal dituen egitura honek (2. irudia) ezaugarri bikainak eskaintzen ditu. Horien artean, gardentasun koloregabea eta egonkortasun termiko itzela aurkitzen dira.

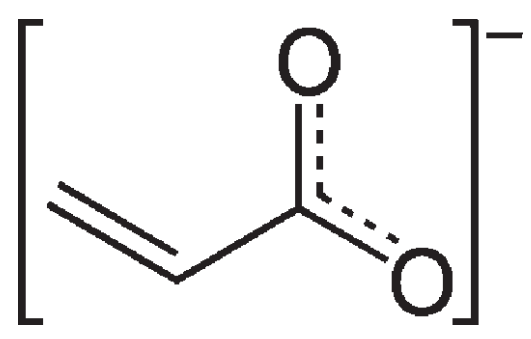

2. irudia. Talde akrilikoaren eskema. 
Leiarrak ekoizterako orduan, lehen oinarri akrilikodun polimeroa poli(metilmetakrilato)a (PMMA) izan zen (1. taula). Hala ere, homopolimero hori hainbat kopolimeroren aurrekaria izan da eta, gaur egun, kopolimero berri asko asmatu dira biobateragarritasun hobea izan dezaten gehienbat.

1.taula. PMMAren ezaugarri optikoak.

\begin{tabular}{cc}
\hline \multicolumn{2}{c}{ Poli(metilmetakrilato)a (PMMA) } \\
\hline \multicolumn{2}{c}{ Errefrakzio-indizea } \\
$486,1 \mathrm{~nm}$ & 1,497 \\
$589 \mathrm{~nm}$ & 1,491 \\
$656,3 \mathrm{~nm}$ & 1,489 \\
Transmisioa $(\%)$ & $92-95$ \\
Lan-tenperatura max. $\left({ }^{\circ} \mathrm{C}\right)$ & $72{ }^{\circ} \mathrm{C}$ \\
Ur-absortzioa $(\%)$ & 0,3 \\
\hline
\end{tabular}

\subsection{Oftalmologia eta ukipen-leiarrak}

Ukipen-leiarrak Xx. mendean sortu zituzten Adolf Fick-ek eta Edouard Kalt-ek. Oftalmologian aurrerapen handien izan duen arloa izan da leiarrena. Gaur egun, ikusmenaren hainbat arazo konpontzeko erabiltzen dira, hala nola, ukipen-lenteak, begi-barneko lenteak (IOLs ingelesez), orbital-horma artifizialak, kornea artifizialak, glaukoma filtraziorako inplanteak eta ordezkapen-pieza biskoelastikoak besteak beste. Aplikazio horiek guztiak biomaterialei esker egin daitezkeela esan daiteke, material horien ezaugarriak oso desiragarriak baitira begi-barneko atalen inplanteak edo leiarrak egiteko.

Ukipen-leiarrak ikusmen-akatsak zuzentzeko edo helburu estetikoz kornearen gainean jartzen eta eusten diren lente mehe eta kurbatuak dira. Lente horiei eskatzen zaie argi ikusgaiaren transmisio ona izatea, oxigeno-iragazkortasunaren maila altua edukitzea, ioi-iragazkortasun egokia eta kimikoki egonkorra izatea, eroaletasun termiko aproposa edukitzea eta ekoizten errazak eta merkeak izatea. Honenbestez, ukipen-leiarren fabrikaziorako erabiliko diren materialak berebiziko garrantzia izango du ezaugarri horiek lortzerako orduan.

Polimeroz ekoiztu ziren lehen ukipen-leiarrak PMMAz (Plexiglass izen komertziala) eginak zeuden (3. irudia). Horiek zurrunak ziren, baina kaleratu zirenean, oso erabiliak beren propietate optikoak zirela eta. Errefrakzio-indizeak beirarenak baino hobeak ziren, iraunkortasun altua zuten eta malko-filmaren osagaien deposizioekiko erresistentzia egokia zuten. Baina oxigeno-iragazkortasun eskasa eta begiaren forma aldatzeko joera zela eta, beren erabilera asko mugatu zen. 


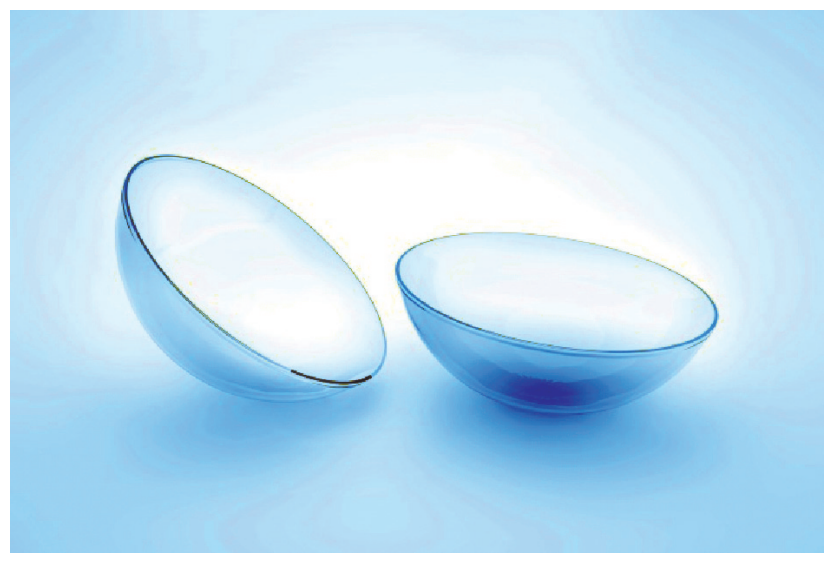

3. irudia. Polimerozko ukipen-leiarrak.

60. hamarkadan, poli(2-hidroxietilmetakrilato)a (PHEMA) asmatu zen eta PMMAri merkatua murriztu zion. Izan ere, Otto Wichterler-en asmakizun horrek lenteei leuntasuna eta, ondorioz, erosotasuna eman zien. Horretarako, hidrogela eta ur-kantitate handiak gordetzeko gaitasuna zuen gurutzapen agente bat erabili ziren. Hala ere, oxigeno-iragazkortasun eskasa zuten, eta horrek kornearen metabolismoari eragiten zion. Eragozpen hori monomero hidrofilikoak kopolimerizatuz gainditu zen, ur-eduki handikoak baitira. Hurrengo hamarkadan, ordea, zurrunak ziren eta gas-iragazkortasun handia zuten ukipen-leiarrak (RGP ingelesez) asmatu ziren. Horiek ekoizteko, metilmetakrilato monomeroa (MMA) oxigeno-iragazkortasun maila altua emango dion beste monomero batekin (2,2,2-trifluoroetil metakrilatoa,TFEMA; hexafluoroisopropil metakrilatoa, HFIM; edota 2-Amino-2(hidroximetil)-1,3-propanediola, TRIS) kopolimerizatu zen.

Ukipen-leiarrez gain, oftalmologian erabili ohi diren beste lente polimeriko batzuk begi-barnekoak dira (4. irudia). Lente horiek Bigarren Mundu Gerran sortu zituen Harold Ridley-k hegazkin-gidariek hobeto ikus zezaten, baina berehala katarata-ebakuntza pairatu zuten zibilen artean erabiltzen hasi zen. Oso arrakastatsuak izan ziren irudi garbia ikusteko bide optiko argia zutelako eta biobateragarritasun-denbora oso luzeak zituztelako.

Nahiz eta lehen begi-barneko lenteak PMMAz eginak izan, material horrek begi-inguruko ehunak kaltetzen zituenez, oinarri akrilikozko material ezberdinak erabiltzen hasi ziren ukipen-leiarrekin gertatu zen bezalaxe.

Aurkezten den lan honek lenteak egiteko erabili diren hainbat materialen ezaugarriak eta zenbait neurketa azaldu nahi ditu, industrian erabiltzen diren parametroak nola kalkulatzen diren eta material komunek zein balio 


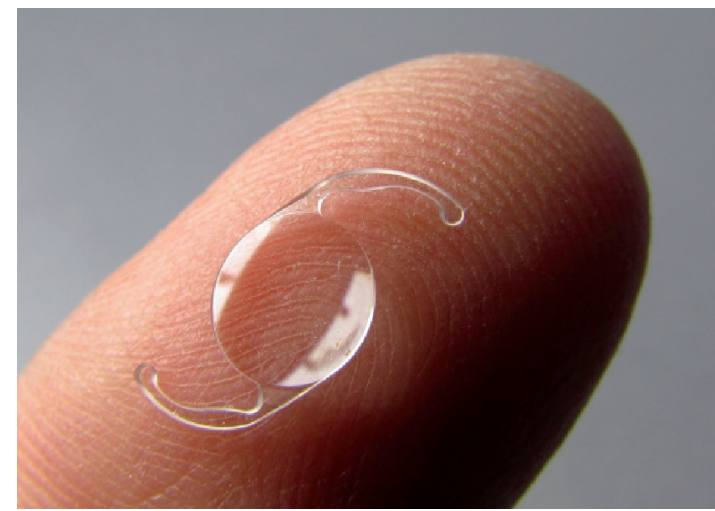

4. irudia. Lehenengo begi-barneko leiarra.

duten azaltzeko. Horrela, aski ezaguna den PMMAz gain, poli(tert-butilakrilato)a (PTBA) eta poli(bentzilakrilato)a (PBA) aztertu dira, beren degradazio termikoa, prozesu horren zinetika eta isuritako gasen espektro ezberdinak analizatuz.

\section{FASE ESPERIMENTALA}

\subsection{Materialak}

Tert-butilakrilatoa (Aldrich, \% 98) eta bentzilakrilatoa (Alfa Aesar, $\%$ 97) hutsean destilatuak izan ziren inhibitzaileak kentzeko. Erabilitako hasarazlea 2,2'-Azobis(2-metilpropionitrilo)a (AIBN) (Fluka) izan zen eta dietil eterrean egindako kristaltzearen bidez purifikatua izan zen. Polimerizazioa gauzatzeko erabilitako disolbatzaileak eman bezala erabili ziren.

\subsection{Polimeroen sintesia}

Poli(tert-butilakrilato)a eta poli(bentzilakrilato)a erradikal askeko polimerizazio erradikalario baten bidez prestatu ziren, bentzenotan, $70{ }^{\circ} \mathrm{C}$-tan, nitrogenozko atmosferan eta monomero mol totalen \% 1 AIBN erabiliz. Soberako disolbatzailea lurrungailu birakarian lurrundu zen, polimeroak tetrahidrofurano (THF) kantitate txikian disolbatu eta ur hotzean hauspeatu ziren. Azkenik, eskuratutako materialak 2 egunez hutsean lehortu ziren giro-tenperaturan.

Batez besteko pisu molekularrak gelaren permeazio-kromatografiaren (GPC) teknikaren bidez determinatu ziren dimethilformamida (DMF) disolbatzaile gisa erabiliz, aurrez poliestireno patroiekin kalibratutako zutabeekin. 
Polimero akrilikoak oftalmologian. Degradazio-prozesuaren analisia

\subsection{Beira-trantsiziozko tenperaturaren $\left(\boldsymbol{T}_{g}\right)$ neurketak}

Polimeroen $\mathrm{T}_{\mathrm{g}}$ a neurtzeko, DSC822e modeloko Mettler Toledo ibiltze diferentzialeko kalorimetroa (DSC) erabili zen. Lagin bakoitza $0{ }^{\circ} \mathrm{C}$-tik $100{ }^{\circ} \mathrm{C}$-rainoko izozte/berotze zikloetan jarri zen $T_{g}$ balio errepikagarriak lortzeko. Beroketak $20{ }^{\circ} \mathrm{C} \cdot \mathrm{min}^{-1}$ abiadurarekin burutu ziren eta beira-trantsiziozko tenperaturak oinarri-lerroaren eta inflexio-zonaldearen kurba tangentearen estrapolazioz neurtu ziren.

\subsection{Analisi termograbimetrikoak}

Polimeroen degradazioa eta egonkortasun termikoa determinatzeko, DTG-60 Shimadzu termobalantza erabili zen. Laginak (10-15 mg) girotenperaturatik $700{ }^{\circ} \mathrm{C}$-raino berotu ziren. Analisia gauzatzeko, 5, 10 eta $20^{\circ} \mathrm{C} \cdot \mathrm{min}^{-1}$-eko abiadurak erabili ziren nitrogenozko atmosferapean.

\subsection{Zinetikaren metodologia}

Material baten degradazio zinetikoa zein den jakitea garrantzitsua da degradazioaren prozesu eta propietateekin erlazionatutako denborak eta tenperaturak aztertzeko. Halaber, zinetika oso erabilia da prozesu termikoen mekanismoak ulertzeko eta garatzeko. Beraz, horren helburua modu pragmatikoan, tenperaturaren, denboraren eta konbertsioaren artean erlazio matematikoa garatzea da [3-4].

Orokorrean, ikerketa zinetiko horiek baldintza ez-isotermikoak erabiltzen dituzten analisi termograbimetrikoen bidez gauzatzen dira. Tenperatura jakin baterako degradazio-prozesu baten konbertsio-gradua $(\alpha)$ (1) ekuazioan definitzen da:

$$
\alpha=\frac{m_{0}-m_{T}}{m_{0}-m_{f}}
$$

non $m_{T} T$ tenperaturako masa den eta $m_{0}$ eta $m_{f}$ hasierako eta amaierako masak diren hurrenez hurren. Baldintza ez-isotermikoetako degradazioabiadura (2) ekuazioan definitzen da:

$$
\frac{d \alpha}{d t}=k(T) f(\alpha)
$$

non $k(T)$ tenperaturaren mende dagoen abiadura konstantea den eta $f(\alpha)$ konbertsio diferentzial funtzioa den. Arrhenius ekuazioaren arabera, $k(T)-\mathrm{a}$ (3) ekuazioan definitzen da:

$$
k(T)=A \exp \left(-\frac{E a}{R T}\right)
$$


non $A$ faktore pre-esponentziala, Ea aktibazio-energia eta $R$ gas konstante unibertsala diren.

Berotze-abiadura konstante baterako, $\beta=d T / d t$, (2) eta (3) ekuazioen arteko konbinazioa (4) ekuazioan adierazten da:

$$
\beta \frac{d \alpha}{d t}=A \exp \left(-\frac{E a}{R T}\right) f(\alpha)
$$

(4) ekuazioaren berrantolatzeak (5)-eko erlazioa sortzen du degradazio ez-isotermikoentzat, dagokion konbertsioa erabiliz:

$$
g(x)=\int_{0}^{T} \frac{d \alpha}{f(\alpha)}=\frac{A}{\beta} \int_{0}^{T} \exp \left(-\frac{E a}{R T}\right) d T
$$

Zinetika-ikerketak, normalean, metodo termograbimetrikoen bitartez gauzatzen dira baldintza ez-isotermoetan. Modu ez-isotermoetan egiten diren analisi zinetiko gehienetan, Kissinger-Akahira-Sunose (KAS) [5] eta Flynn-Wall-Ozawa (FWO) [6-8] metodoak erabiltzen dira. Metodo horiek beren oinarria isokonbertsio printzipioan dutenez, metodo isokonbertsional bezala ezagutzen dira, eta oso erabilgarriak dira erreakzio konplexuen degradazio zinetikoa aztertzeko.

Flynn-Wall-Ozawa metodoa, (6) ekuazioa, Doyle hurbilketan oinarriturik dagoen eredu askeko metodoa da eta hurrengo ekuazioaren bitartez deskriba daiteke:

$$
\ln \beta=c-1.052\left(\frac{E a}{R T}\right)
$$

non $\beta$ berotze-abiadura (gure ikerketan: $5,10,15,20 \mathrm{~K} \cdot \mathrm{min}^{-1}$ ), c konstante bat, $T$ tenperatura, Ea aktibazio-energia eta $R$ gasen konstante unibertsala diren. Konbertsio-gradu konstanterako, $\alpha, \ln \beta$ versus $1 / T$ grafikoak $-1.052(E a / R)$ lerro zuzeneko malda eman behar du.

Coats eta Redfern hurbilketetan [9] oinarria duen Kissinger-Akahira-Sunose metodoak, (7) ekuazioak, $\ln \left(\beta / T^{2}\right)$ versus $1 / T$ grafikoak $-E a / R$ maldadun lerro zuzena eman beharko luke.

$$
\ln \frac{\beta}{T^{2}}=c-\frac{E a}{R T}
$$

Lan honetan, akrilatotik eratorritako polimero ezberdinen degradaziozinetika aztertuko dugu Flynn-Wall-Ozawa metodoan oinarrituta. 
Polimero akrilikoak oftalmologian. Degradazio-prozesuaren analisia

\section{EMAITZAK ETA EZTABAIDA}

Behin polimeroen sintesia eginik, horien karakterizazioa egin zen. Lehenik, pisu molekularra eta beira-trantsizioa neurtu ziren, GPCa eta DSCa erabilita hurrenez hurren. Polimeroen karakterizazioaren emaitzak 2. taulan laburturik ikus daitezke.

2. taula. GPCaren eta DSCaren emaitzak.

\begin{tabular}{lcccc}
\hline \multicolumn{1}{c}{ Polimeroa } & $\begin{array}{c}\mathrm{Mn}\left(10^{4}\right) \\
\left(\mathrm{g} \cdot \mathrm{mol}^{-1}\right)\end{array}$ & $\begin{array}{c}\mathrm{Mw}\left(10^{4}\right) \\
\left(\mathrm{g} \cdot \mathrm{mol}^{-1}\right)\end{array}$ & $i$ & $T_{g}\left({ }^{\circ} \mathrm{C}\right)$ \\
\hline PTBA & 27,3 & 35,8 & 1,3 & 45 \\
PBA & 13,4 & 22,6 & 1,7 & 5 \\
PMMA & 34,5 & 37,7 & 1,1 & 123 \\
\hline
\end{tabular}

\subsection{Egonkortasun termikoa}

Lorturiko polimeroen egonkortasun termikoa aztertzeko, TGA saiakuntzak erabili ziren. TGAtik eskuratutako termogramek polimero bakoitzaren degradazio-etapak aztertzea ahalbidetzen dute; gainera, akoplaturik dagoen infragorriari esker (FTIR), degradazioan zehar emititutako gasak determinatzea ere posible da. Gas horiek aztertuta, material bakoitzaren degradazio-mekanismoa determinatzea posible da. Lan honetan aztertutako materialen termogramak 5 . irudian agertzen dira, kasu honetan $10 \mathrm{C} \mathrm{min}{ }^{-1}$-eko berotze-abiadurarekin neurtuak.

TGArekin batera termograbimetria diferentziala (DTG) agertzen da, TG kurbaren lehenengo deribatua tenperaturarekiko adieraziz. DTG kurbak prozesu edo etapa ezberdinen amaierako eta hasierako tenperatura identifikatzen laguntzen du eta, gainera, gainezarritako prozesuak argiago adierazten ditu.

Polimeroen termogramak aztertuta, poli(tert-butilakrilato)a hiru etapatan degradatzen da eta $240{ }^{\circ} \mathrm{C}$-ra arte termikoki egonkorra dela beha daiteke, hor hasten baita degradazioaren lehenengo etapa (5.a. irudia) eta $\%$ 9,6ko hondakin-masa uzten du; gainera, lehengo etapan masaren \% 40 galtzen duela azpimarratu behar da. Poli(bentzilakrilato)a, berriz, etapa bakar batean degradatzen da, termikoki egonkorra da $360^{\circ} \mathrm{C}$-ra arte (5.b. irudia) eta $\%$ 6,3ko hondakin-masa uzten du. Azkenik, poli(metilmetakrilato) a etapa bakar batean degradatzen da (5.c. irudia), $335^{\circ} \mathrm{C}$-tan hasten da eta ez du hondakin-masarik uzten. Beraz, esan daiteke poli(bentzilakrilato)a termikoki egonkorragoa dela, bere degradazio termikoa tenperatura altuagoetan gertatzen baita. 
a)

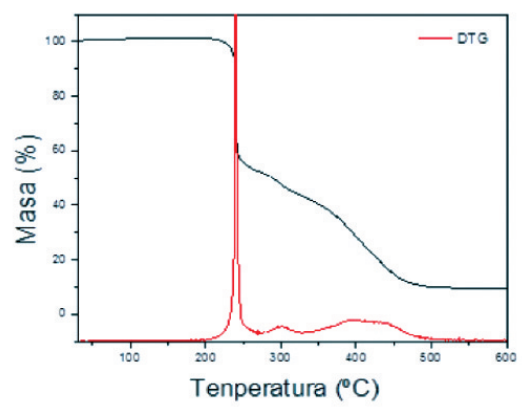

c)

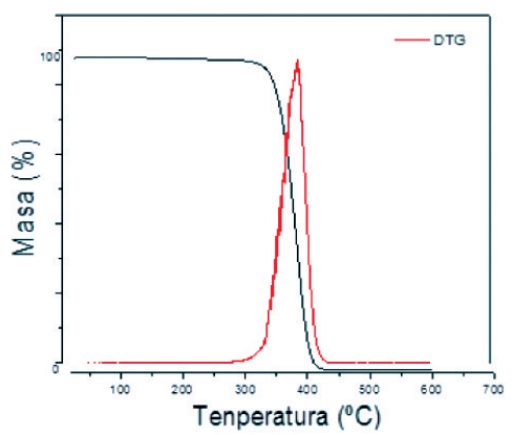

b)

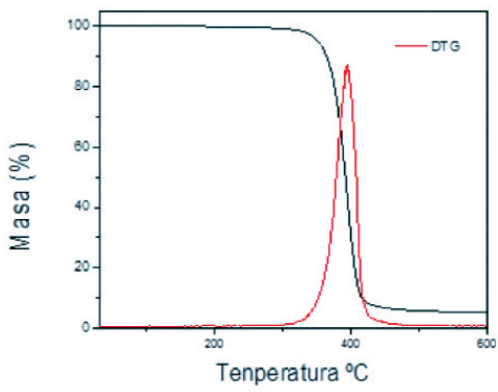

5. irudia Polimeroen TGA eta DTG kurbak $\left(10^{\circ} \mathrm{C} \mathrm{min}^{-1}\right.$-eko berotze-abiadurarekin neurtuak), a) poli(tert-butilakrilato)a; b) poli(bentzilakrilato)a; c) poli(metilmetakrilato)a.

Termograbimetriaren etapa bakoitzean gertatzen diren prozesuak ulertzeko, degradaziotik askatutako gasak FTIR bidez analizatu ziren (6. irudia). Teknika horren bitartez, polimeroen degradazioan gertatzen diren loturen apurketa ezberdinak ezagutzea posible da.

Lehenik eta behin, poli(tert-butilakrilato)aren degradaziotik askatutako gasak aztertu dira 6.a. irudian azaltzen diren espektroez baliatuta. $240{ }^{\circ} \mathrm{C}$ tan gertatzen da degradazio nagusia eta bertan (tert-butilakrilato) albo-taldea kate nagusitik banatzen da alkano taldearen $\mathrm{C}-\mathrm{H}$ bibrazioen tentsioak (2.900-3.100 $\left.\mathrm{cm}^{-1}\right)$ ageri baitira, $\mathrm{C}=\mathrm{O}\left(1.650 \mathrm{~cm}^{-1}\right)$ tentsio-bandekin batera. Degradazio-etapa hori amaitzean, $300{ }^{\circ} \mathrm{C}$-tik aurrera, $\mathrm{CO}_{2}$-ren presentzia nabaria da $\left(2.360 \mathrm{~cm}^{-1}\right)$.

Ondoren, poli(bentzilakrilato)a degradaziotik askatutako gasak aztertu dira (6.b. irudia). $360^{\circ} \mathrm{C}$-tan gertatzen da degradazio edo etapa bakarra eta 
a)

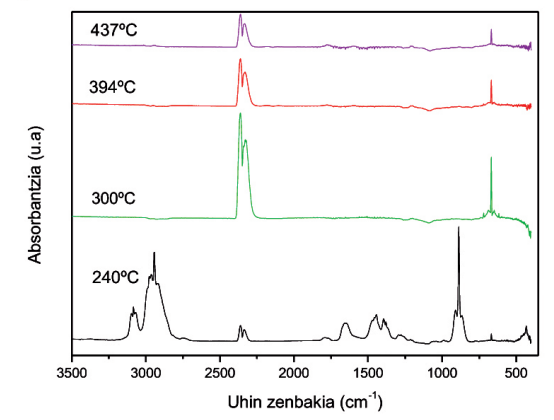

b)

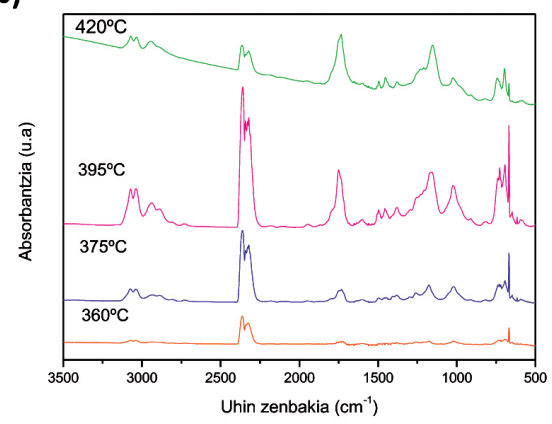

c)

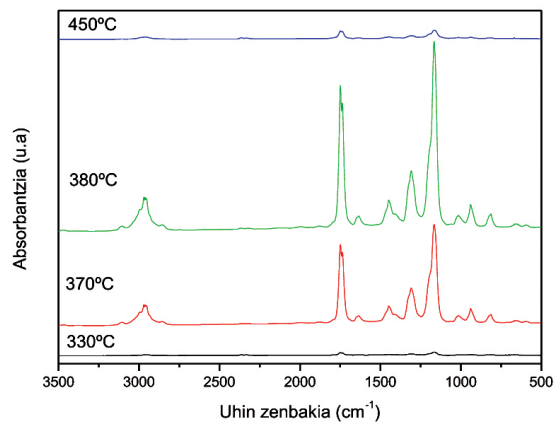

6. irudia. Polimeroen TGAtik askatutako gasen FTIR espektroa, a) poli(tert-butilakrilato)a; b) poli(bentzilakrilato)a; c) poli(metilmetakrilato)a.

hiru puntu aztertu dira. $360^{\circ} \mathrm{C}$-tan hasten da degradazioa eta bertan $\mathrm{CO}_{2^{-}}$ ren presentzia da bandarik aipagarriena $\left(2.360 \mathrm{~cm}^{-1}\right) .375^{\circ} \mathrm{C}$-tan degradazioaren erdia gertatu da jada, eta aurreko $\mathrm{CO}_{2}$-aren presentziarekin batera eraztun aromatikoaren $=\mathrm{C}-\mathrm{H}$ tentsioak $\left(3.100 \mathrm{~cm}^{-1}-3.000 \mathrm{~cm}^{-1}\right)$ eta gaintonoak nabarmentzen dira, $\mathrm{C}=\mathrm{O}$ tentsio-bandez gain. Banda horien irakurketek tenperatura konkretu horretan albo-taldeak kate nagusitik banatzen direla adierazten dute. Azkenik, $395^{\circ} \mathrm{C}$-tan gertatzen da degradazio nagusia eta bertan aurreko espektroen banden intentsitateak nabarmen handitu direla ikusten da, karbonilo taldearen banda gailenduz $\left(1.750 \mathrm{~cm}^{-1}\right)$.

Azkenik, PMMAren degradazio-etapa bakarra gertatzen da, $380{ }^{\circ} \mathrm{C}$ tan, eta lau puntu aztertu dira (6. c. irudia). Lehenengoa $330{ }^{\circ} \mathrm{C}$-tan, bigarrena degradazioaren erdia baino gehiago gertatu denean, $370{ }^{\circ} \mathrm{C}$-tan, hirugarrena degradazio osoan, $380{ }^{\circ} \mathrm{C}$-tan, eta azkena degradazioa amaitzean, $450{ }^{\circ} \mathrm{C}$-tan. Puntu guztietan banda berdinak beha daitezke, baina intentsitate ezberdinarekin. FTIR bandarik aipagarrienak alkano taldearen $\mathrm{C}-\mathrm{H}$ bibrazioen tentsioak $\left(2.900 \mathrm{~cm}^{-1}\right)$, eta $\mathrm{CH}_{2}$ taldearen $\mathrm{C}-\mathrm{H}$ flexio simetriko eta antisimetrikoak (1.200-1.500 $\left.\mathrm{cm}^{-1}\right)$ dira. Beha daitekeen beste banda ga- 
rrantzitsu bat ester taldearena da $\left(1.740 \mathrm{~cm}^{-1}\right)$. Beste kasuetan ikusi den bezala, azken honetan ere albo-taldeak kate nagusitik banatzen dira degradazioa hasi bezain laster, baina kasu honetan ezberdina dena degradazio hori ez dela $\mathrm{CO}_{2}$-aren askapenarekin batera gertatzen.

\subsection{Degradazio-zinetika eta aktibazio-energia}

Polimeroen degradazio-zinetika eta \% 5 eta \% 90 konbertsio-tarteko aktibazio-energien emaitzak 7. irudian agertzen dira. Aktibazio-energiak

a)
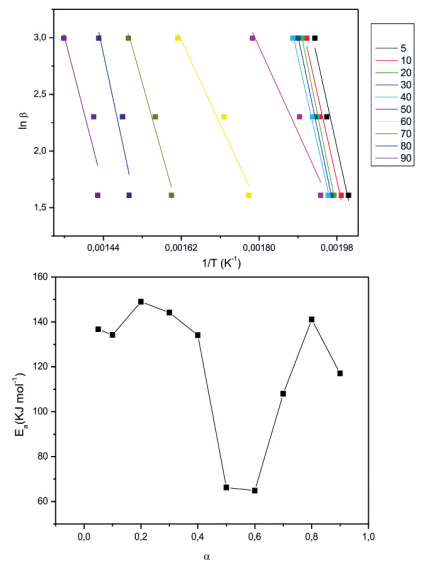

b)
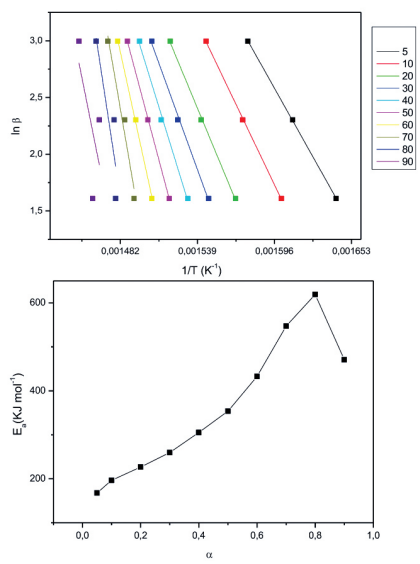

c)
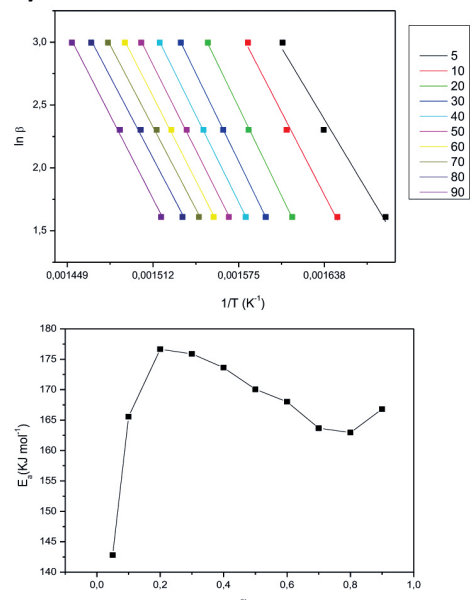

7. irudia. Polimeroen Flynn-Wall-Ozawa grafikoak (goian) eta aktibazio-energien aldaketak konbertsio-graduekiko (behean), a) poli(tertbutilakrilato)a; b) poli(bentzil akrilato)a; c) poli(metilmetakrilato)a. 
Polimero akrilikoak oftalmologian. Degradazio-prozesuaren analisia

irudikatutako zuzenen maldetatik kalkulatu ziren. Horiek konbertsio-graduaren funtzioan aztertuta, poli(tert-butilakrilato) (7.a. irudia) polimeroaren aktibazio-energian aldaketak beha daitezke, degradazio-prozesuan zehar gertatzen diren prozesuak direla eta. Poli(tert-butilakrilato)aren degradazioprozesua hiru etapetan gertatzen da, lehenengoa, $139,6 \mathrm{~kJ} \cdot \mathrm{mol}^{-1}$-eko batez besteko aktibazio-energiarekin, bigarrena, $65,5 \mathrm{~kJ} \cdot \mathrm{mol}^{-1}$ batez besteko aktibazio-energiarekin eta, hirugarrena, $122 \mathrm{~kJ} \cdot \mathrm{mol}^{-1}$ batez besteko aktibazio-energiarekin.

Hala ere, nahiz eta poli(bentzilakrilato) eta PMAA polimeroen TGA degradazio-prozesuan etapa bakarra agertu, aktibazio-energiak aztertzean (7. b eta 7. c irudiak) beha daiteke PMMAren kasuan aktibazio-energia 142,8 eta $176,6 \mathrm{~kJ} \cdot \mathrm{mol}^{-1}$ tartean dagoela eta pentsa daiteke, zuzenen arteko malden aldaketak txikiak direla kontuan hartuta, degradazio-etapa sinple bat dagoela. Gainera, PMMAren degradazioaren kasuan, lorturiko emaitzak bibliografian lortutakoekin konpara eta berrets daitezke [10]. Bestalde, poli(bentzilakrilato)aren kasuan, aktibazio-energiaren aldakuntza askoz handiagoa da, $167,7-619 \mathrm{~kJ} \cdot \mathrm{mol}^{-1}$; horrek pentsarazten digu TGAn degradazio-etapa bakar bat bezala agertu arren, hori mekanismo konplexuen bitartez gertatzen dela.

\section{ONDORIOAK}

Poli(tert-butilakrilato), poli(bentzilakrilato) eta poli(metilmetakrilato) polimeroen degradazio-zinetika hiru berotze-abiaduraren bidezko neurketa termograbimetrikoen bitartez determinatzea posible izan da. Flynn-WallOzawa metodoaren bitartez, degradazio-etapen aktibazio-energiak determinatu dira. Gainera, polimero bakoitzak degradazio-prozesuan askatu dituen gasak aztertu dira.

Hori guztia aztertuta ikusi da poli(bentzilakrilato)a dela aztertutako hiru polimeroen artean egonkorrena, $360{ }^{\circ} \mathrm{C}$-an degradatzen baita. Gainera, azken hori poli(metil metakrilato)arekin batera, fase bakarrean degradatzen da eta poli(tert-butilakrilato)a, berriz, hiru fasetan .

\section{ESKER ONAK}

Egileek egindako lana Eusko Jaurlaritzari eskertu nahi diote jasotako diru-laguntzagatik (Euskal unibertsitate publikoko ikertzaile-taldeen ekintzak babesteagatik, IT718-13 eta FRONTIERS (ELKARTEK)).

Gainera, Mikel Azkunek Euskal Herriko Unibertsitateko Euskara Errektoreordetzari eskertu nahi lioke tesia euskaraz egiteko bekaren onuraduna den partetik. 


\section{BIBLIOGRAFIA}

[1] http://www.aoa.org.(2016-05-05)

[2] BÄUMER S. 2010. Handbook of Plastic Optics, Wiley-VCH.Weinheim.

[3] CHEN S.M., SHIH Y.F. 2016. «Thermal stability and degradation behaviour hydroxyethylmethacrylate-poli(lactide) polymers». Journal of Macromolecular Science, Part A, 53, 125-131.

[4] LI, Q., WANG Y., FAN M., ZHANG J., CHENG J. 2016. «Thermal degradation kinetics of poly(acrylate/ $\alpha$-methyl styrene». APolymer Degradation and stability, 128, 158-164.

[5] KISSINGER H.E. 1957. «Reaction Kinetics in Differential Thermal Analysis». Analytical Chemistry, 29, 1702-1706.

[6] OZAWA T. 2000. «Thermal analysis - review and prospect». Thermochimica Acta, 355, 35-42.

[7] FLYNN J.H., WALL L.A. 1966. «A quick, direct method for the determination of activation energy from thermogravimetric data». Journal of Polymer Science. Part B: Polymer Letters, 4,323-328.

[8] FLYNN J.H., WALL L.A. 1966. «General treatment of the thermogravimetry of polymers ». Journal of Research of the National Bureau of StandardsA.Physics and Chemistry, 70A, 487-523.

[9] COATS A.W., REDFERN J.P. 1964.«Kinetic Parameters from Thermogravimetric Data ». Nature, 201, 68-69.

[10] AZIMI H.R., REZAEI, M., MAJIDI F. 2014, «The non-isothermal degradation kinetics of St-MMA copolymers». Polymer Degradation and Stability, 99, 240-248. 